\title{
Numerical study of heat transfer deterioration of turbulent supercritical kerosene flow in heated circular tube
}

\author{
Guoxin Dang, Fengquan Zhong*, Yongjiang Zhang, Xinyu Zhang \\ State Key Laboratory of High Temperature Gas Dynamics, Institute of Mechanics, Chinese Academy of Sciences, Beijing 100190, China
}

\section{A R T I C L E I N F O}

\section{Article history:}

Received 30 October 2014

Received in revised form 8 January 2015

Accepted 17 February 2015

Available online 7 March 2015

\section{Keywords:}

Supercritical kerosene

Convective heat transfer

Turbulent flow

Numerical study

\begin{abstract}
A B S T R A C T
Turbulent flow and convective heat transfer of supercritical kerosene flow in an axisymmetrically heated circular tube with a diameter of $2 \mathrm{~mm}$ and at a mass flow rate range of $0.0015-0.015 \mathrm{~kg} / \mathrm{s}$ and a wall heat flux range of $0.15-2.0 \mathrm{MW} / \mathrm{m}^{2}$ are numerically studied using Reynolds averaged Navier-Stokes method with a two-layer turbulence model. The thermophysical and transport properties of kerosene are determined by a 10-species surrogate with the Extended Corresponding State method. Mesh dependency is first investigated and numerical results of fuel and wall temperatures are compared with experimental data for validations. The results show that flow properties such as velocity and Reynolds number increase significantly along the axial direction as the fuel temperature rises and kerosene undergoes the state transition from liquid to supercritical state. Deterioration of convective heat transfer is found to occur when the wall heat flux exceeds a critical value and at the same time, the wall temperature approaches the pseudo-critical temperature of kerosene. The present results show that deterioration of heat transfer are attributed to the development of turbulent properties in the near-wall region based on the results of turbulent kinetic energy and turbulence production term. The relation between the critical heat flux $\left(q_{w c}\right)$ for occurrence of heat transfer deterioration and the mass flux $(G)$ is studied and a fitting formula of $q_{w c}$ and $G$ is obtained.
\end{abstract}

(c) 2015 Elsevier Ltd. All rights reserved.

\section{Introduction}

Regenerative cooling using onboard hydrocarbon fuels as coolant is considered to be one of the most effective methods for rocket and scramjet thermal protections [1,2]. In a regenerative cooling system, hydrocarbon fuel flows through cooling channels and absorbs heat of engine wall via heat convection before being injected into combustor. Characteristic of convective heat transfer of hydrocarbon fuels is one of the most important fundamental issues for cooling design and optimization. It has been known that the working pressure of fuel is usually higher than its critical value $\left(P_{c}\right)$ and along the cooling path, fuel temperature would increase and exceed its critical temperature $\left(T_{c}\right)$ so that hydrocarbon fuel becomes supercritical without going through a two-phase dome region. Compared to gaseous or liquid state, supercritical fluid presents many of unique features [3-5]. It has gas-like transport property, relatively large density similar to liquid and very high solubility. The thermophysical and transport properties of

\footnotetext{
* Corresponding author at: Bei-Si-Huan-Xi Road \#15, Institute of Mechanics, Chinese Academy of Sciences, Beijing 100190, China. Tel.: +86 1082543838.

E-mail address: fzhong@imech.ac.cn (F. Zhong).
}

supercritical fluid such as density, specific heat, viscosity, and thermal conductivity have remarkable variations with temperature and pressure near the critical point and there exists a peak of specific heat at a temperature as so called "pseudo-critical temperature" $\left(T_{p c}\right)$. Therefore, flow and heat transfer properties of supercritical hydrocarbon fuels are significantly different from those of simple liquids and could result in heat transfer deterioration or enhancement. It is worth noticing that understanding heat transfer deterioration or enhancement is critical for cooling design. Therefore, it is imperative to study characteristics of convective heat transfer of supercritical hydrocarbon fuels at flow conditions relevant to rocket or scramjet applications.

Most of previous studies on convective heat transfer of supercritical fluids are focused on simple fluids such as water [6], carbon dioxide [7,8], and hydrocarbons of small molecules such as methane $[9,10]$. Ward et al. [11] numerically investigated flow and heat transfer properties of mildly cracked alkanes at supercritical conditions. Urbano and Nasuti [12] numerically studied heat transfer of supercritical methane. The critical value of ratio of wall heat flux to specific mass flow rate for the onset of heat transfer deterioration and its dependency on pressures were investigated. In another recent paper [13], Urbano and Nasuti studied 
flow and wall heat flux conditions for the occurrence of heat transfer deterioration for varied light hydrocarbons including methane, ethane and propane. More recently, Ruan et al. [14] calculated turbulent flow and heat transfer of $n$-decane with pyrolytic reaction at supercritical pressures. Very limited studies about heat transfer of supercritical hydrocarbon fuels such as kerosene or diesel have been reported, of which the majority are experimental studies. Linne et al. [15] studied supercritical heat convection and thermal cracking of JP-7 fuel with an electrically heated pipe system. Zhong et al. [16] investigated heat transfer of China RP-3 aviation kerosene at a Reynolds number range of $3 \times 10^{3}-3 \times 10^{5}$ and a wall heat flux range of $50-300 \mathrm{~kW} / \mathrm{m}^{2}$ with a two-stage heating facility. The deterioration and enhancement of heat transfer of kerosene flow were observed. Hu et al. ${ }^{[17]}$ experimentally inspected heat transfer of kerosene at high wall heat fluxes $\left(5-10 \mathrm{MW} / \mathrm{m}^{2}\right)$. They identified the occurrence of heat deterioration in the region where the inner wall temperature is close to the pseudo-critical temperature. Due to difficulties in the measurement of fluid temperature inside small pipe with a diameter of a few millimeters, most of the experiments discuss only overall performance of convective heat transfer in terms of the measured inlet and outlet fuel temperatures and mass flow rate, lacking of details of the change in flow and heat transfer properties along the pipe length. At the same time, due to hundreds of species in kerosene and its complex thermophysical properties, numerical simulation of kerosene flow, especially turbulent flow, encounters many of difficulties and so far, very few relevant numerical works have been reported.

In this paper, turbulent convective heat transfer of supercritical aviation kerosene in a heated, straight and horizontally placed circular tube is numerically studied. The Reynolds averaged NavierStokes equations are solved with a two-layer turbulence model, including the RNG $k-\varepsilon$ turbulence model and the Wolfstein one-equation model in the near-wall region. Thermal and transport properties of kerosene are determined by a 10 -species surrogate proposed in our previous work [16] for China RP-3 aviation kerosene with the Extended Corresponding State method (ECS) [18]. The present numerical method is validated via study of mesh dependency and comparisons of wall and fuel temperatures with experimental data. Based on the present results, deterioration of convective heat transfer of kerosene are observed and the associated turbulent flow mechanisms are discussed. Effects of mass flow rate and wall heat flux on heat transfer properties are studied as well as the issue of critical heat flux for occurrence of heat transfer deterioration. The present study is expected to provide further insights into mechanisms of supercritical heat transfer and reference data for design and optimization of cooling system for rocket and scramjet applications.

\section{Numerical procedures}

\subsection{Computational domain and boundary conditions}

Kerosene flow in a straight and horizontally-placed circular tube with an inner diameter of $2 \mathrm{~mm}$ is studied. The flow is turbulent since the minimum Reynolds number $\operatorname{Re}_{d}$ (at the entrance of heated section of the tube) is 7000 , larger than the critical value of 2300 for turbulent pipe flow. The gravity effect is not included in the present study because the maximum ratio of Grashof number $G r$ to $\operatorname{Re}_{d}^{2}$ is less than $6 \times 10^{-4}$ that is smaller than the threshold value of 0.001 [19] for the consideration of gravity effect. Another issue worth noticing is that for China RP-3 aviation kerosene, pyrolysis occurs when the fuel temperature reaches approximately $800-850 \mathrm{~K}$ at pressures of 3-5 MPa [20]. Hence, heat transfer data analyzed in the paper are limited in the flow region where the wall and the fuel temperatures are both below $800 \mathrm{~K}$.
Fig. 1 gives a sketch of the tube with heat loading. Due to axisymmetry of circular tube flow and wall thermal boundary condition, two-dimensional computation is adopted. Dimensions and boundary conditions of the computational domain are given as below.

(1) The diameter of the tube is $2 \mathrm{~mm}$ and the length is varied from 1 to $2.2 \mathrm{~m}$ according to different cases with varied wall heat flux. As shown in Fig. 1, a 0.1 meter-long flow region without heat loading is calculated upstream of the heated section to obtain a fully developed turbulent pipe flow.

(2) The inlet fuel temperature is $350 \mathrm{~K}$ and the inlet pressure is $3 \mathrm{MPa}$, greater than the critical value of approximately $2.4 \mathrm{MPa}$.

(3) The mass flow rate is in a range of $0.0015-0.015 \mathrm{~kg} / \mathrm{s}$ and correspondingly, the mass flow rate per unit area, i.e. $G$ $\left(G=\frac{\dot{m}}{A}\right)$ is varied from 475 to $4750 \mathrm{~kg} /\left(\mathrm{m}^{2} \mathrm{~s}\right)$. An exponential velocity profile according to fully developed turbulent pipe flow is imposed at the inlet as boundary condition.

(4) The outflow boundary condition with zero gradients of flow velocity along the axial direction [21] is applied at the outlet for fully developed tube or duct flows. The no slip and no penetration boundary are used for the tube wall and a constant heat flux is imposed on the wall of the heated section. The heat flux is changed from 0.15 to $2.0 \mathrm{MW} / \mathrm{m}^{2}$.

\subsection{Numerical method and computational mesh}

The Navier-Stokes equations are solved by finite volume method provide by the density based solver of Fluent 6.3. The 2nd-order upwind scheme is applied for convective terms and 2nd-order central scheme for viscous terms. The RNG $k-\varepsilon$ model is applied for turbulence modeling and the Wolfstein turbulence model [22] is adopted in the near-wall region characterized with low Reynolds number properties. The SIMPLE algorithm is employed to resolve the coupling between velocity and pressure. The implicit Gauss-Seidel iteration is used to calculate the time advancement.

Stretched grids are constructed along the radial direction in the near-wall region. The first grid point to the wall is constructed to ensure $\Delta y^{+} \leqslant 1\left(\Delta y^{+}=\frac{\Delta y}{y_{\tau}}\right.$, where $y_{\tau}$ is the viscous length scale of turbulent flow [23]) and there are more than 10 grids within the viscosity-dominant near-wall region (i.e. $y^{+} \leqslant 11$ ). Since thermophysical properties of kerosene change dramatically at temperatures close to the critical value, the grid size in the vicinity of the wall should be refined to ensure accuracy of the numerical scheme. A uniform mesh is first constructed along the flow direction (for example, the total gird number is $N_{x}=2000$ ) and computation is conducted. The adaptive grid technique based on density gradient of the computational result is then used to refine the grid spacing in the region with large variations of fuel properties and the grid number after the adaption process is increased to 2500 .

The mesh dependence is first investigated. Four meshes are studied. The total grids numbers are 100,000 (case a), 150,000 (case b), 240,000 (case c) and 960,000 (case d) respectively. The tube diameter of the test case is $2 \mathrm{~mm}$ and the wall heat flux is

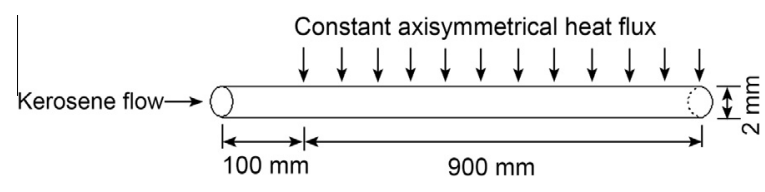

Fig. 1. Sketch of the heated circular tube 

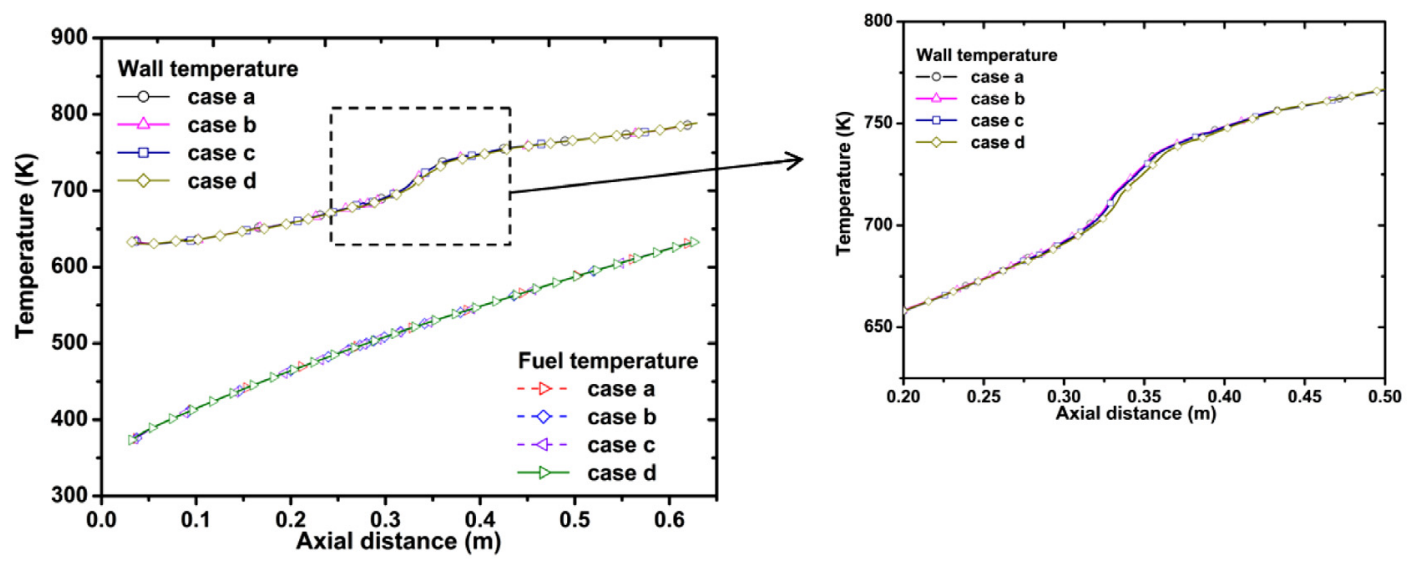

(a)
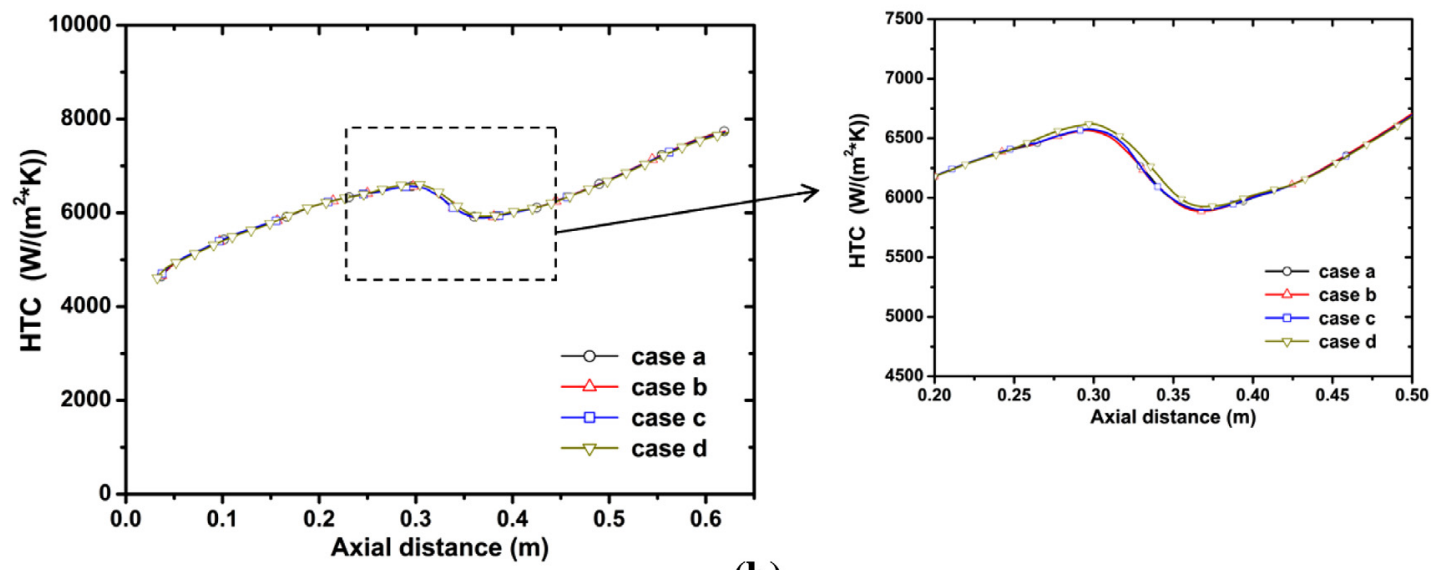

(b)

Fig. 2. (a): Comparison of the wall and the fuel temperatures; (b): comparison of heat transfer coefficient along the axial direction calculated with the four meshes.

set as $1.2 \mathrm{MW} / \mathrm{m}^{2}$.The inlet temperature and pressure is $300 \mathrm{~K}$ and $3 \mathrm{MPa}$ respectively and the mass flow rate is $0.006 \mathrm{~kg} / \mathrm{s}$.

Fig. 2(a) shows comparisons of fuel temperature and wall temperature along the axial distance obtained with the four meshes and Fig. 2(b) is the comparison of heat transfer coefficients (defined as $h=\frac{q_{w}}{T_{w}-T_{f}}$, where $q_{w}$ is the wall heat flux, $T_{w}$ is the wall temperature, $T_{f}$ is the bulk temperature of kerosene as defined as $T_{f}=\frac{\int_{A} \rho u C_{p} T d A}{\int_{A} \rho u C_{p} d A}$, where $\rho$ is density of kerosene, $u$ is velocity, $C_{p}$ is specific heat). As shown in the zoom-in figure of Fig. 2(a), the difference is only seen in the wall temperature curves at locations of $x=0.3-0.4 \mathrm{~m}$ where the wall temperature exceed the pseudo-critical temperature and a maximum discrepancy is found to be $1 \%$. Similarly, Fig. 2(b) shows the difference in heat transfer coefficient is only observed at locations of $x=0.3-0.4 \mathrm{~m}$ and a maximum discrepancy of $1.8 \%$ is found. Therefore, the mesh with 60 grid points in the radius direction and 2500 gird points in the axial direction is adopted.

\subsection{Surrogate of kerosene}

The thermodynamic and transport properties of China RP-3 kerosene are determined by a 10 -species surrogate proposed in our previous work [16] and the Extended Corresponding State method (ECS) [18] with Benedict-Webb-Rubin equation. The species and mole fractions of the surrogate are listed in Table 1. The surrogate of kerosene and its accuracy have been discussed in the literature
[16]. It is found that the values of critical temperature and pressure predicted by the surrogate are very close to the experimental data (discrepancy is $4 \%$ ) and discrepancies of other properties such as density, specific heat et al. are about $8 \%$. Thermal and transport properties of kerosene are tabulated as functions of temperature and pressure and at each computational step, their value at mesh points are updated with 2nd-order interpolation algorithm based on local temperature and pressure.

Fig. 3(a) gives the change of density and specific heat as a function of temperature at a pressure of $3 \mathrm{MPa}$ and Fig. 3(b) presents the change of dynamic viscosity and thermal conductivity with temperature at the same pressure. As shown in the figures, density and viscosity of kerosene decrease remarkably in the vicinity of the critical point $\left(T_{c} \sim 640 \mathrm{~K}, P_{c} \sim 2.4 \mathrm{MPa}\right)$ and a peak of specific heat

Table 1

10-species surrogate for China RP-3 kerosene.

\begin{tabular}{lll}
\hline & Surrogate species & Molar fraction \% \\
\hline Alkanes & $n$-Octane & 6 \\
& $n$-Decane & 10 \\
& $n$-Dodecane & 20 \\
& $n$-Tridecane & 8 \\
& n-Tetradecane & 10 \\
& $n$-Hexadecane & 10 \\
& Methylcyclohexane & 20 \\
Cycloalkanes & Trans-1,3-dimethylcyclopentane & 8 \\
Benzenes & Propylbenzene & 5 \\
Naphthalenes & 1-Methylnaphthalene & 3 \\
\hline
\end{tabular}



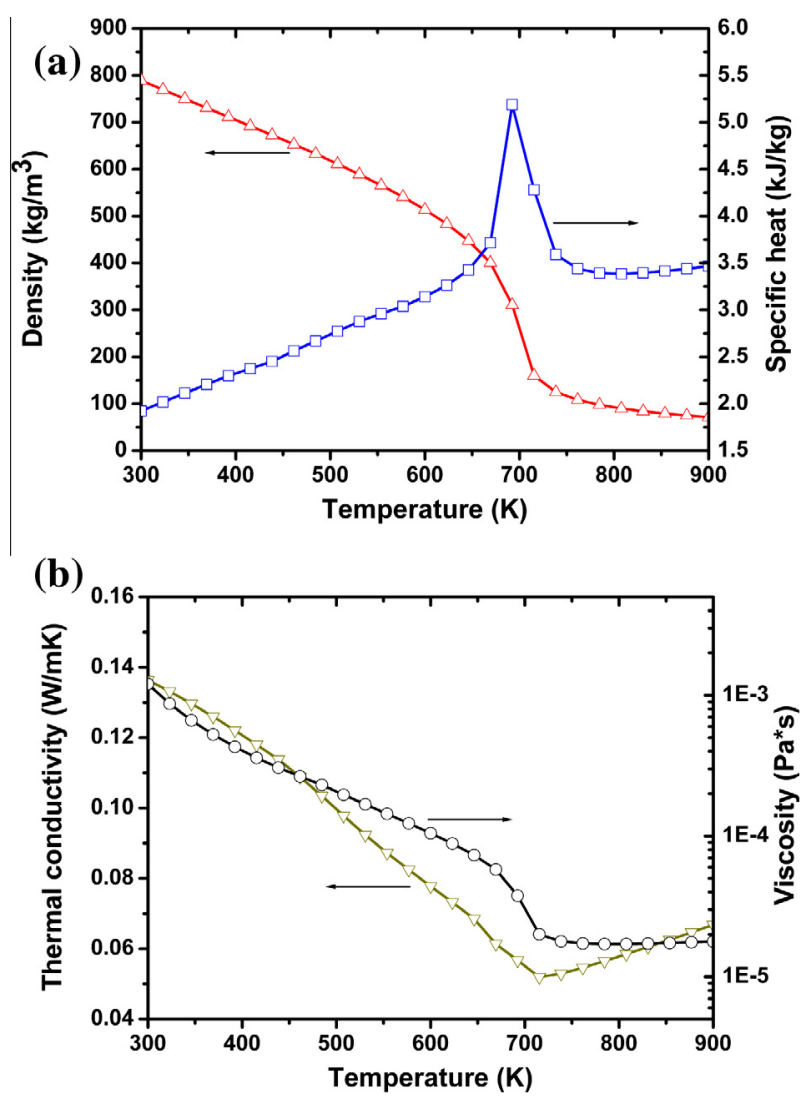

Fig. 3. Variation of kerosene density, specific heat, thermal conductivity and dynamic viscosity as a function of temperature at a pressure of $3 \mathrm{MPa}$.

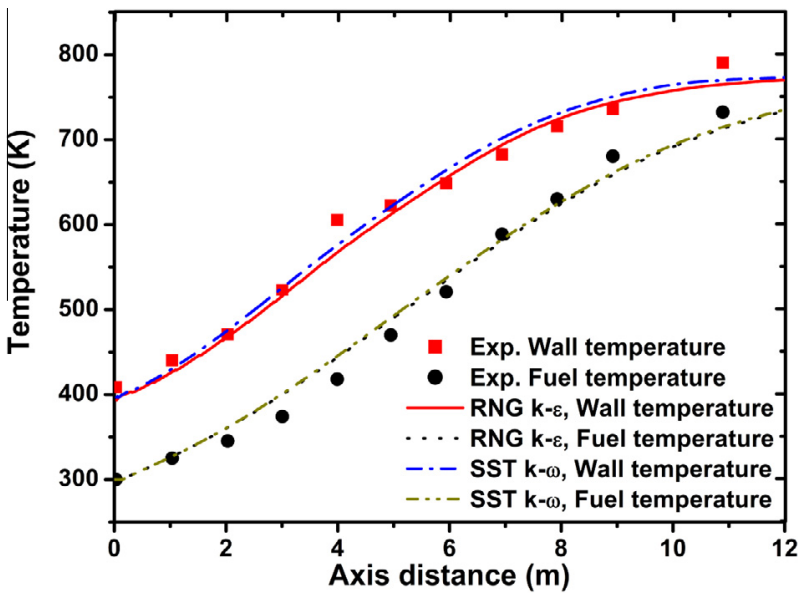

Fig. 4. Comparison of the fuel and wall temperatures obtained with CFD and experiment.

is observed at temperatures close to the pseudo-critical temperature $\left(T_{p c} \sim 690 \mathrm{~K}\right)$. It is expected that flow and heat transfer properties of supercritical kerosene would exhibit unique characteristics due to significant changes in the thermodynamic and transport properties.

\subsection{Validation of the numerical method}

The numerical method is validated by comparing the calculated fuel and wall temperatures with experimental results [16]. The inlet pressure and temperature of China RP-3 kerosene are 4.1 MPa and $300 \mathrm{~K}$, respectively. The mass flow rate per unit area,
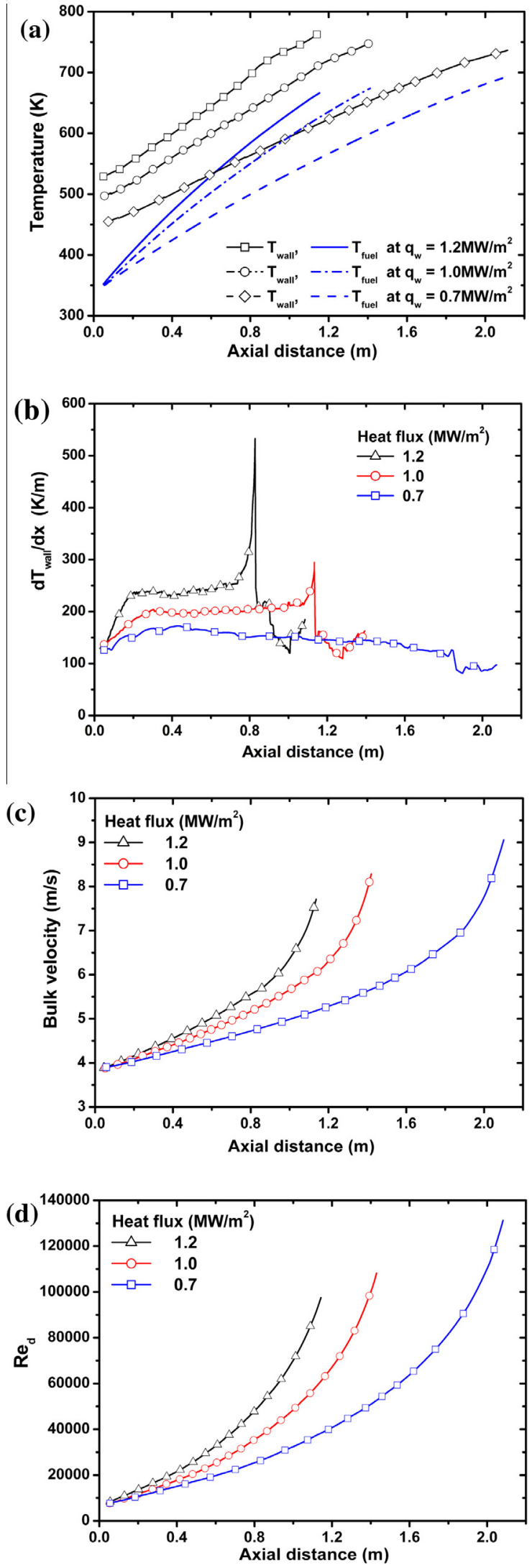

Fig. 5. (a): Distribution of wall and fuel temperatures, (b): $\frac{d T_{\text {wall }}}{d x},(\mathrm{c})$ : bulk velocity, (d): Reynolds number along the axial distance for case- 1 , case- 2 and case- 3 .

$G$ is approximately $750 \mathrm{~kg} /\left(\mathrm{m}^{2} \mathrm{~s}\right)$ and the inlet Reynolds number is 7000. The averaged value of wall heat flux is $230 \mathrm{~kW} / \mathrm{m}^{2}$. 
Fig. 4 gives distribution of fuel temperature and wall temperature along the axial direction obtained with present computation and experimental measurements. The uncertainty of the experimental data is mainly caused by measurement accuracy of thermocouple probe used in experiments and the measurement error for wall and fuel temperatures is approximately $\pm 3 \mathrm{~K}$. As shown in the figure, the numerical results agree well with the experimental data in general. The maximum discrepancy of the wall temperature and the fuel temperature are $7 \%$ and $6 \%$ respectively, proving the accuracy of present numerical method.

Different turbulence models have been tested to study the effect of turbulence model. It is found that RNG $k-\varepsilon$ turbulence model gives the best result compared to the experimental data. Fig. 4 also gives results obtained with SST $k-\omega$ model. As shown in the figure, the wall temperature calculated with RNG $k-\varepsilon$ model is slightly more close to the experimental data than that with SST $k-\omega$ model.

\section{Results and discussions}

\subsection{Deterioration of convective heat transfer}

Three cases with varied wall heat fluxes of $0.7 \mathrm{MW} / \mathrm{m}^{2}$ (case-1), $1.0 \mathrm{MW} / \mathrm{m}^{2}$ (case-2), and $1.2 \mathrm{MW} / \mathrm{m}^{2}$ (case-3) are studied. For the three cases, the inlet pressure is kept at $3 \mathrm{MPa}$, higher than the critical value of $2.4 \mathrm{MPa}$ and the inlet temperature is set as $350 \mathrm{~K}$. The mass flow rate is $0.009 \mathrm{~kg} / \mathrm{s}$ and the value of $G$ (defined as mass flux $\rho u$ ) is 2860 and the inlet Reynolds number is 7000 .
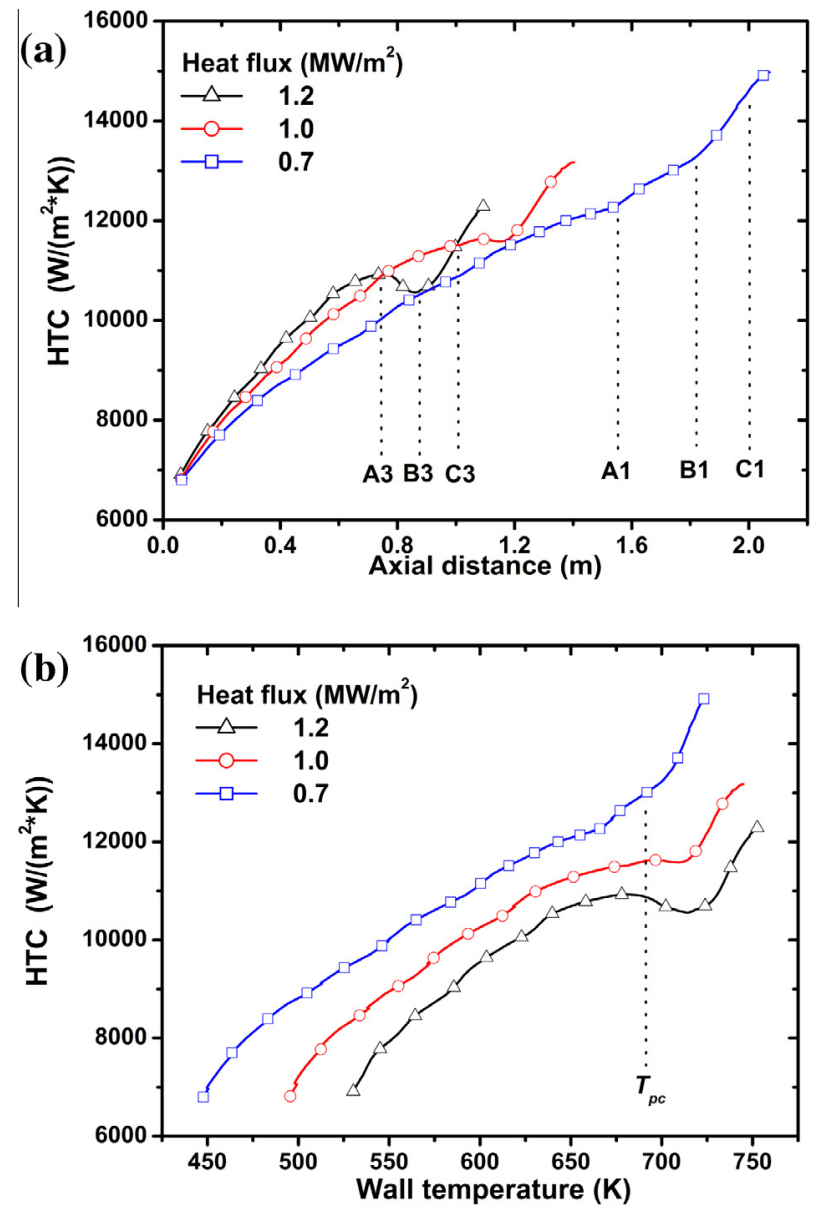

Fig. 6. Distribution of heat transfer coefficient along the axial distance: (a); distribution of heat transfer coefficient as a function of wall temperature: (b).
Fig. 5(a) presents distributions of wall and fuel temperatures along the axial distance for the three cases. As shown in the figure, the fuel temperature increases along the tube length and become higher than the critical temperature $(\sim 640 \mathrm{~K})$ at a certain downstream location. Similarly, wall temperature increases and exceeds the pseudo-critical temperature ( $\sim 690 \mathrm{~K})$. The change of wall temperature can be seen more clearly by plotting the derivative of wall temperature with respective to the axial distance, i.e. $\frac{d T_{\text {wall }}}{d x}$ as shown in Fig. 5(b). A peak of $\frac{d T_{\text {wall }}}{d x}$ is found at the location of $x=0.83 \mathrm{~mm}$ for case- 3 and of $x=1.14 \mathrm{~mm}$ for case- 2 respectively, where the wall temperature reaches approximately the pseudo-critical value. As for case- 1 with a heat flux of $0.7 \mathrm{MW} / \mathrm{m}^{2}$, no peak of $\frac{d T_{\text {wall }}}{d x}$ is found, and the change (increasing) of wall temperature does not show any unusual trends.

Fig. 5(c) and (d) give the change of fuel bulk velocity and Reynolds number along the tube length. It is clearly seen that fuel velocity increase significantly due to reduction in the density as fuel temperature rises, especially in the region of state transition from liquid to supercritical. Compared to the inlet Reynolds number of 7000, the outlet Reynolds number is larger than 100,000, increased by 2 orders in the magnitude, which is caused by remarkable decrease in the viscosity as a result of the fuel temperature rising from 350 to $700 \mathrm{~K}$.

Fig. 6(a) plots distributions of heat transfer coefficient as a function of axial distance. As shown in Fig. 6(a), for case-1 with $q_{w}$ of $0.7 \mathrm{MW} / \mathrm{m}^{2}$, heat transfer coefficient increases monotonously along the axial direction since Reynolds number increases from 7000 at the inlet to more than $10^{5}$ at the outlet as indicated in Fig. 5(c). For case-2 with $q_{w}$ of $1.0 \mathrm{MW} / \mathrm{m}^{2}$ and case- 3 with $q_{w}$ of
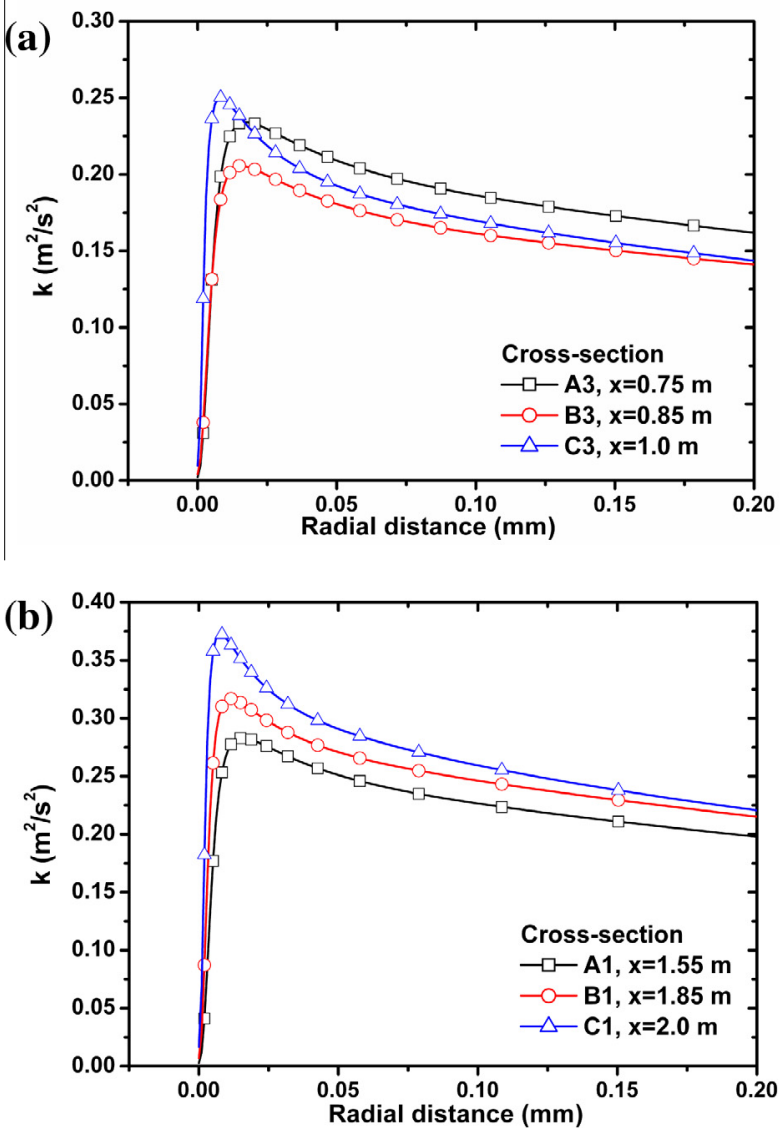

Fig. 7. Distribution of turbulence kinetic energy $k$ in the near-wall region at different streamwise locations (a) case-3; (b) case-1. 
1.2 $\mathrm{MW} / \mathrm{m}^{2}$, heat transfer coefficient, however, exhibits a decrease in the region of $x=1.1-1.2 \mathrm{~m}$ and $x=0.75-0.85 \mathrm{~m}$ respectively as shown in Fig. 6(a). The decrease in heat transfer coefficient indicates the existence of heat transfer deterioration when the wall heat flux is higher than a certain value. For both case- 2 and case3 , deteriorations in convective heat transfer are not severe due to the wall heat fluxes with not sufficiently high values for scramjet applications. It indicates that heat transfer deterioration should be considered in cooling design, but is not so dangerous that it could overthrow the whole design process. Comparing the result of case- 2 and case-3, it is found that the degree of heat transfer deterioration is weakened as wall heat flux decreases. Fig. 6(b) plots the change of heat transfer coefficient as a function of wall temperature. It is seen that for the cases with heat transfer deterioration, the deterioration starts to happen at the axial location where the wall temperature approaches the pseudo-critical temperature of approximately $690 \mathrm{~K}$. The results reveal that heat transfer deterioration would occur only when the wall temperature is close to the pseudo-critical temperature of kerosene and at the same time, the wall heat flux exceeds a certain value (The threshold of wall heat flux for the occurrence of heat transfer deterioration is found to be related to mass flow rate per unit area and a detailed discussion is addressed in Section 3.3). Results at other flow conditions also confirm the same fact and they are not given here due to limit of pages. Similar phenomena have been reported by other studies of pure fluids such as water [24] and methane $[9,10]$.

(a)
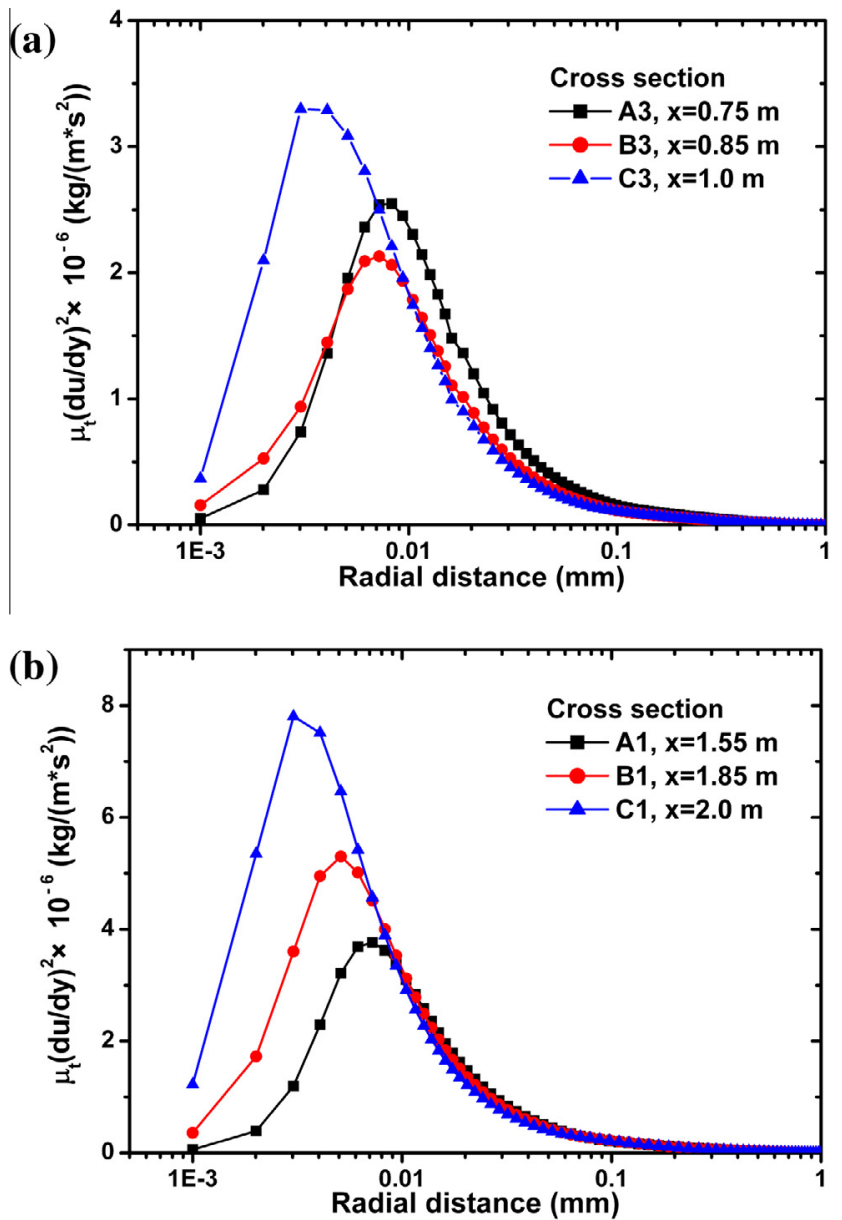

Fig. 8. Distribution of turbulence production term $P_{k}$ in the near-wall region at different streamwise locations (a) case-3; (b) case-1.

\subsection{Characteristics of turbulent flow}

The flow is fully turbulent since Reynolds number at the entrance is 7000 and it increases along the flow path. It is known that convective heat transfer is strongly related to the turbulent flow especially in the vicinity of the wall. Fig. 7(a) and (b) give turbulent kinetic energy $k$ (defined as $k=\frac{\overline{u^{\prime 2}}+\overline{v^{\prime 2}}+\overline{w^{\prime 2}}}{2}$, where $u^{\prime}, v^{\prime}, w^{\prime}$ are velocity fluctuations of the three components) in the near wall region at three cross-sections as indicated in Fig. 6(a) for case-1 and case-3. For case-3, the three cross section of A3, B3 and C3 are located respectively upstream of, within and downstream of the region where heat transfer deterioration occurs and kerosene transits from liquid to supercritical state. The three cross sections of $\mathrm{A} 1, \mathrm{~B} 1$ and $\mathrm{C} 1$ are also across the state transition region for case-1, in which no heat transfer deterioration is observed.

As mentioned before, deterioration of heat transfer occurs for cases with wall heat fluxes of 1 and $1.2 \mathrm{MW} / \mathrm{m}^{2}$ and it does not happen for case- 1 with a low heat flux of $0.7 \mathrm{MW} / \mathrm{m}^{2}$. Fig. 7(a) shows distribution of turbulent kinetic energy $k$ along the radial direction at cross sections of $\mathrm{A} 3, \mathrm{~B} 3$ and $\mathrm{C} 3$ for case-3. In the figure, the zero point of horizontal axis denotes the wall. It is seen that turbulent kinetic energy reaches a minimum value at cross section of $\mathrm{B} 3$, corresponding to the heat transfer deterioration. When looking at Fig. 7(b) with distributions of $k$ at three cross sections of A1, $\mathrm{B} 1$ and $\mathrm{C} 1$, turbulent kinetic energy continues to increase along the flow direction and no minimum value is found at cross section of B1. The present results reveal that heat transfer deterioration is related to evolution of turbulent flow in the near-wall region as
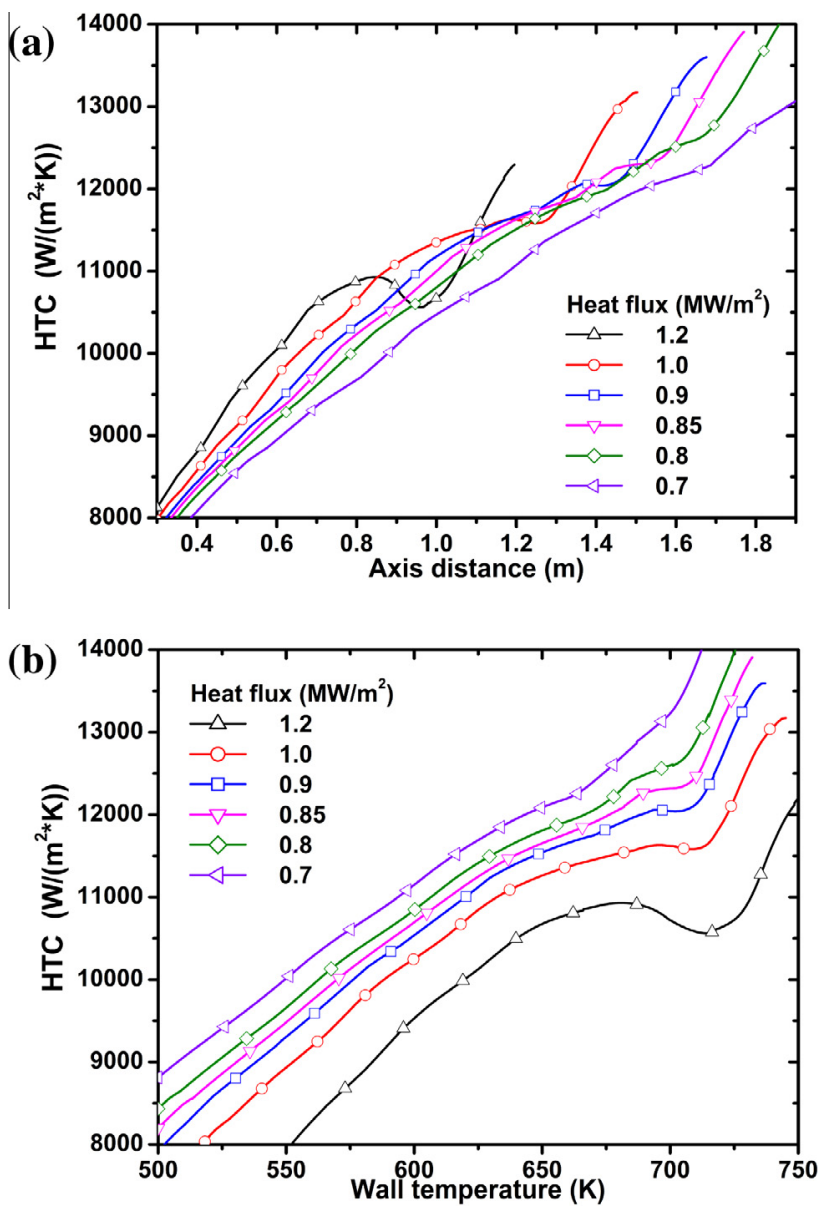

Fig. 9. Distributions of heat transfer coefficient with axial distance (a) and wall temperature (b) at varied wall heat fluxes for $G=2860 \mathrm{~kg} /\left(\mathrm{m}^{2} \mathrm{~s}\right)$. 
indicated by the development of turbulent kinetic energy as shown in Fig. 7.

To further understand variations of near-wall turbulence during the state change of kerosene. Fig. 8(a) and (b) give distribution of turbulence production term $P_{k}$ (defined as $P_{k}=\mu_{t}\left(\frac{\partial \bar{u}}{\partial r}\right)^{2}$, where $\mu_{t}$ is turbulent viscosity and $\bar{u}$ is the mean axial velocity component) along the radial direction at the three cross sections of case- 3 and case- 1 respectively. As we know that $P_{k}$ caused by the velocity gradient, is the major production for near-wall turbulence $[23,25]$. As shown in Fig. 8(a), $P$ has a minimum value at cross section $B 3$ which is consistent with the change of turbulent kinetic energy plotted in Fig. 7(a). For case-1, Fig. 8(b) shows that $P_{k}$ always increases along the axial direction and does not show any decreasing trends.

As a summary, it is believed that for the present small tube and inlet flow conditions, heat transfer deterioration attributes to significant variations in thermodynamic and transport properties of kerosene as its temperature approaches pseudo-critical value in the near-wall region, which affects the turbulent transport properties.

\subsection{The critical heat flux}

The above results have shown that deterioration of heat transfer occurs when the wall temperature approaches the pseudo-critical temperature and at the same time, wall heat flux must exceed a certain value. It is well known that for liquids such as water, when wall heat flux is larger than a critical value, heat transfer in the near-wall region becomes so called "film boiling" and heat
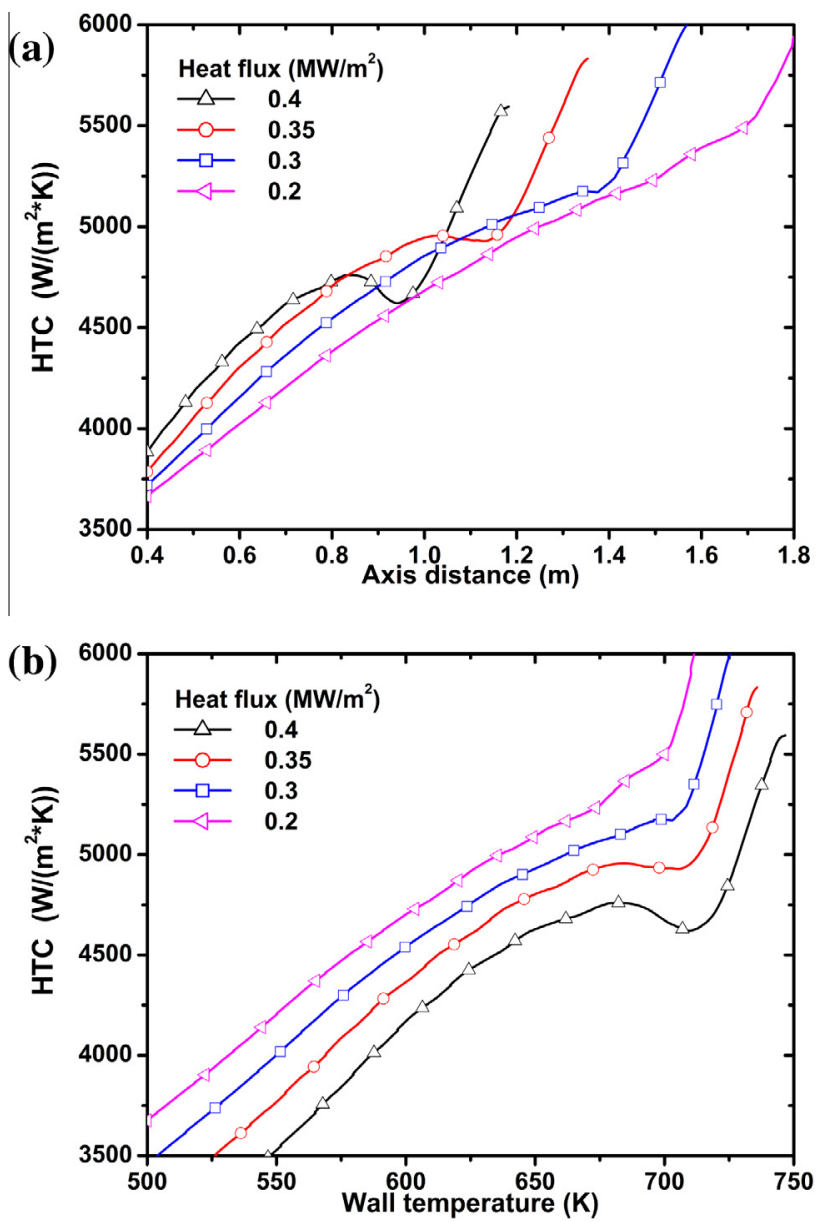

Fig. 10. Distributions of heat transfer coefficient with axial distance (a) and wall temperature (b) at varied wall heat fluxes for $G=950 \mathrm{~kg} /\left(\mathrm{m}^{2} \mathrm{~s}\right)$. exchange efficiency decreases remarkably. Ackerman et al. [26] argued that heat transfer deterioration of supercritical fluid may attribute to a similar phenomenon as called as "pseudo-film boiling". Lee et al. [27] indicated that occurrence of pseudo-film boiling depends on the wall heat flux and the critical heat flux $q_{w c}$ for occurrence of heat transfer deterioration is a function of mass flow rate per unit area $G$. Based on the study of critical heat flux of water, Sudo et al. [28] proposed a relation between critical heat flux $q_{w c}$ and $G$ in the following formation:

$q_{w c}=c \cdot G^{\alpha}$

where, $\alpha$ is the power index and $c$ is a constant. For water flow, $\alpha$ is found to be approximately 0.61 .

To obtain the relation of $q_{w c}$ with $G$ for heat transfer of supercritical kerosene, a series of cases with the same inlet pressure and temperature ( $3 \mathrm{MPa}, 350 \mathrm{~K}$ ) and different $G$ of 475,950 , 1900,2860 , and $4750 \mathrm{~kg} /\left(\mathrm{m}^{2} \mathrm{~s}\right)$ are numerically studied. For a specific value of $G$, kerosene flows with varied wall heat flux are calculated and whether or not heat transfer deterioration occurs is identified. In this way, the critical heat flux for a specific $G$ can be determined. Fig. 9(a) and (b) present distributions of heat transfer coefficient with the axial distance and with the wall temperature for the cases with $G$ of $2860 \mathrm{~kg} /\left(\mathrm{m}^{2} \mathrm{~s}\right)$. As shown in the figures, heat transfer deterioration starts at wall heat flux higher than $0.85-0.9 \mathrm{MW} / \mathrm{m}^{2}$. Fig. 10(a) and (b) give distributions of heat transfer coefficient for cases with $G$ of $950 \mathrm{~kg} /\left(\mathrm{m}^{2} \mathrm{~s}\right)$. The occurrence of heat transfer deterioration is found at wall heat flux higher than approximately $0.3 \mathrm{MW} / \mathrm{m}^{2}$. Similarly, heat transfer results at $G$ of $4750 \mathrm{~kg} /\left(\mathrm{m}^{2} \mathrm{~s}\right)$ and with wall heat flux from 1.3 to 2.0 $\mathrm{MW} / \mathrm{m}^{2}$ are plotted in Fig. 11(a) and (b). Table 2 summarizes
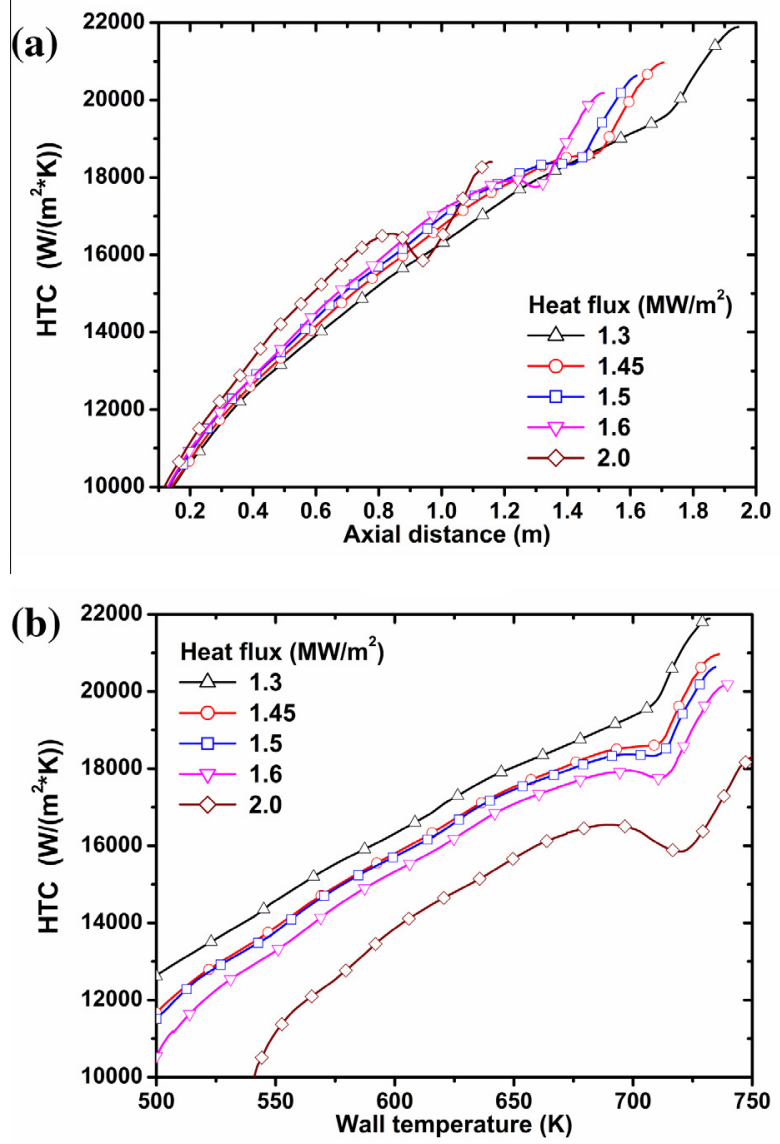

Fig. 11. Distributions of heat transfer coefficient with axial distance (a) and wall temperature (b) at varied wall heat fluxes for $G=4750 \mathrm{~kg} /\left(\mathrm{m}^{2} \mathrm{~s}\right)$ 
Table 2

Flow parameters and heat transfer results of the test cases.

\begin{tabular}{|c|c|c|c|}
\hline$G\left(\mathrm{~kg} /\left(\mathrm{m}^{2} \mathrm{~s}\right)\right)$ & Case \# & $\begin{array}{l}\text { Wall heat flux } \\
\left(\mathrm{MW} / \mathrm{m}^{2}\right)\end{array}$ & $\begin{array}{l}\text { Heat transfer } \\
\text { deterioration or not? }\end{array}$ \\
\hline \multirow[t]{3}{*}{475} & $1-a$ & 0.2 & Yes \\
\hline & $1-b$ & 0.175 & Yes \\
\hline & $1-c$ & 0.15 & No \\
\hline \multirow[t]{4}{*}{950} & $2-a$ & 0.4 & Yes \\
\hline & $2-b$ & 0.35 & Yes \\
\hline & $2-c$ & 0.3 & No \\
\hline & $2-d$ & 0.2 & No \\
\hline \multirow[t]{6}{*}{1900} & $3-a$ & 0.8 & Yes \\
\hline & $3-b$ & 0.7 & Yes \\
\hline & $3-c$ & 0.6 & Yes \\
\hline & $3-d$ & 0.55 & No \\
\hline & $3-e$ & 0.5 & No \\
\hline & $3-f$ & 0.4 & No \\
\hline \multirow[t]{6}{*}{2860} & 4-a & 1.2 & Yes \\
\hline & $4-b$ & 1.0 & Yes \\
\hline & 4-c & 0.9 & Yes \\
\hline & $4-d$ & 0.85 & No \\
\hline & 4-e & 0.8 & No \\
\hline & $4-\mathrm{f}$ & 0.7 & No \\
\hline \multirow[t]{5}{*}{4750} & $5-a$ & 2.0 & Yes \\
\hline & $5-b$ & 1.6 & Yes \\
\hline & $5-c$ & 1.5 & Yes \\
\hline & $5-d$ & 1.45 & No \\
\hline & 5-e & 1.3 & No \\
\hline
\end{tabular}

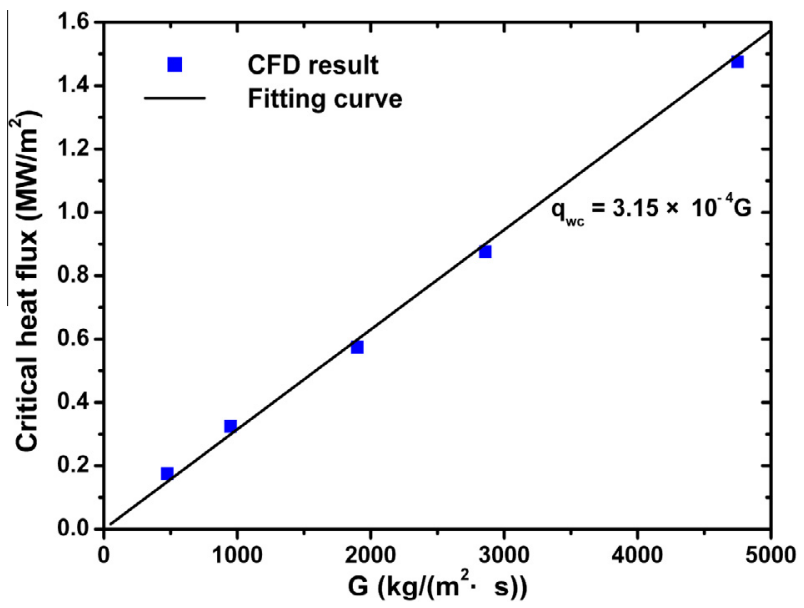

Fig. 12. Variation of critical heat flux with $G$ and the fitting line.

results of all the cases at varied $G$ and wall heat flux and with or without heat transfer deterioration.

Fig. 12 plots the critical heat flux as a function of mass flow rate per unit area $G$ based on the above results. The critical heat flux is found to increase almost linearly with $G$ and a fitting line of $q_{w c}=3.15 \times 10^{-4} G\left(q_{w c}\right.$ is in a unit of $\left.\mathrm{MW} / \mathrm{m}^{2}\right)$ with a standard derivation of $6 \%$, is presented in the figure. Similarly, for critical heat flux of supercritical methane, Urbano and Nasuti [10] got the power of unity for $G$. As shown in the figure, the fitting line divides the figure into two regions, above which the wall heat flux is higher than the critical value and heat transfer deterioration could occur, and below which heat transfer deterioration does not happen.

\section{Conclusions}

In this paper, turbulent flow and convective heat transfer of China RP-3 aviation kerosene at supercritical conditions in a straight and horizontally-placed circular tube are numerically studied with a two-layer turbulence model and a 10-species fuel surrogate combined with the Extended Corresponding State method (ECS). The present numerical method is validated by the study of grid dependence and the comparison of wall and fuel temperatures obtained with numerical simulation and experiments. Flow and heat transfer properties of kerosene during the state change as temperature rises are studied. Heat transfer deterioration and the associated flow mechanism are discussed. Based on the present results, a few conclusions can be drawn as follows.

(1) The flow properties of kerosene such as velocity and Reynolds number increase significantly along the axial direction as its temperature rises and undergoes the state transition from liquid to supercritical state.

(2) Deterioration of convective heat transfer occurs when the wall heat flux exceeds a critical value (i.e. the critical heat flux) and at the same time, wall temperature approaches the pseudo-critical temperature of kerosene. Degree of the heat transfer deterioration diminishes as the wall heat flux decreases.

(3) The deterioration of heat transfer is found to be related to the turbulence properties in the near wall region. The turbulent kinetic energy $k$ and the turbulence production term $P$ in the vicinity of wall present minimum values at cross sections where heat transfer deterioration occurs.

(4) The critical heat flux for the occurrence of heat transfer deterioration is found to be in a linear relation with the mass flow rate per unit area $G$. Based on the numerical results, a linear equation of $q_{w c}=3.1 \times 10^{-4} G$ is obtained for the determination of critical heat flux for turbulent kerosene flow at supercritical conditions.

It is worth noticing that the present relation of $q_{w c}$ and $G$ is obtained on the heat transfer results at a pressure of $3 \mathrm{MPa}$. As pressure rises, heat transfer deterioration weakens and the critical heat flux increases for the same value of $G$. Therefore, a follow up study of the relation of critical heat flux with pressures as well as further validations on the quantitative relation of $q_{w c}$ by heat transfer experiments of kerosene flow at moderate mass flow rate per unit area ( $G=1000-5000)$ is currently underway.

\section{Conflict of interest}

None declared.

\section{Acknowledgment}

This work is funded by Natural Science Foundation of China under Contract No. 11172309.

\section{References}

[1] D.H. Petley, S.C. Jones, Thermal management for a Mach-5 cruise aircraft using endothermic fuel, J. Aircr. 29 (1992) 384-389.

[2] D.R. Sobel, L.J. Spadaccini, Hydrocarbon fuel cooling technologies for advanced propulsion, ASME J. Eng. Gas Turbines Power 119 (1997) 344-351.

[3] R.C. Hendricks, R.J. Simoneau, R.V. Smith, Survey of heat transfer to nearcritical fluids, NASA Technical Note, D-5886, 1970.

[4] J. Bellan, Supercritical (subcritical) fluid behavior and modeling: drops, streams, shear and mixing layers, and sprays, Prog. Energy Combust. Sci. 26 (329) (2000).

[5] V. Yang, Modeling of supercritical vaporization, mixing and combustion processes in liquid-fueled propulsion system,, Proc. Combust. Inst. 28 (2000) 925-942.

[6] E. Stewart, P. Stewart, A. Watson, Thermo-acoustic oscillation in forced convection heat transfer to supercritical pressure water, Int. J. Heat Mass Transfer 16 (1973). 
[7] S. Liao, T. Zhao, Measurements of heat transfer coefficients from supercritical carbon dioxide flowing in horizontal mini/micro channels, J. Heat Transfer 124 (3) (2002).

[8] X.-L. Huai, S. Koyama, T.-S. Zhao, An experimental study of flow and heat transfer of supercritical carbon dioxide in multi-port mini channels under cooling conditions, Chem. Eng. Sci. 60 (12) (2005).

[9] Y.-Z. Wang, Y.-X. Hua, H. Meng, Numerical studies of supercritical turbulent convective heat transfer of cryogenic-propellant methane, J. Thermophys. Heat Transfer 24 (3) (2010) 490-500.

[10] A. Urbano, F. Nasuti, Parametric analysis of heat transfer to supercriticalpressure methane, J. Thermophys. Heat Transfer 26 (3) (2012) 450-463.

[11] T. Ward, J. Ervin, R. Striebich, S. Zabarnick, Simulation of flowing mildlycracked normal alkanes incorporating proportional product distributions, J. Propul. Power 20 (3) (2004) 394-402.

[12] A. Urbano, F. Nasuti, Onset of heat transfer deterioration in supercritical methane flow channels, J. Thermophys. Heat Transfer 27 (2) (2013) 298-308.

[13] A. Urbano, F. Nasuti, Conditions for the occurrence of heat transfer deterioration in light hydrocarbons flows, Int. J. Heat Mass Transfer 65 (2013) 599-609.

[14] B. Ruan, H. Meng, V. Yang, Simplification of pyrolytic reaction mechanism and turbulent heat transfer of n-decane at supercritical pressures, Int. J. Heat Mass Transfer 69 (2014) 455-463.

[15] D.L. Linne, M.L. Meyer, Evaluation of heat transfer and thermal stability of supercritical JP-7 fuel, AIAA Paper 97-3041 (1997).

[16] F.-Q. Zhong, X.-J. Fan, G. Yu, J.-G. Li, C.-J. Sung, Heat transfer of aviation kerosene at supercritical conditions, J. Thermophys. Heat Transfer 23 (3) (2009) 543-550.

[17] Z.-H. Hu, T.-K. Chen, Y.-S. Luo, J.-X. Zheng, Heat transfer to kerosene at supercritical pressure in small-diameter tube with large heat flux, J. Chem. Ind Eng. 53 (2) (2002) 134-138.
[18] J.W. Leach, P.S. Chappelear, T.W. Leland, Use of molecular shape factors in vapor-liquid equilibrium calculations with the corresponding states principle, AIChE J. 14 (1968) 568-576.

[19] S. Kakac, The effect of temperature-dependent fluid properties on convective heat transfer, in: Handbook of Single-phase Convective Heat Transfer, John Wiley \& Sons, New York, 1987, pp. 18.1-18.56.

[20] F.-Q. Zhong, X.-J. Fan, G. Yu, J.-G. Li, C.-J. Sung, Thermal cracking and heat sink capacity of aviation kerosene under supercritical conditions, J. Thermophys. Heat Transfer 25 (3) (2011) 450-456.

[21] X.-F. Li, F.-Q. Zhong, X.-J. Fan, X.-L. Huai, J. Cai, Study of turbulent heat transfer of aviation kerosene flows in a curved pipe at supercritical pressure, Appl. Therm. Eng. 30 (2010) 1845-1851.

[22] M. Wolfstein, The velocity and temperature distribution of one-dimensional flow with turbulence augmentation and pressure gradient, Int. J. Heat Mass Transfer 12 (1969) 301-318.

[23] F.M. White, Viscous Fluid Flow, second ed., McGraw-Hill Inc, 1991.

[24] K. Yamagata, K. Nishikawa, S. Hasegawa, T. Fujii, S. Yosida, Forced convective heat transfer to supercritical water flowing in tubes, Int. J. Heat Mass Transfer 15 (12) (1972) 2575-2593.

[25] J.H. Ferziger, M. Peric, Computational Methods for Fluid Dynamics, SpringerVerlag, 1996.

[26] J.W. Ackerman, Pseudoboiling heat transfer to supercritical pressure water in smooth and ribbed tubes, J. Heat Transfer Trans. ASME 92 (3) (1970) 490-497.

[27] R.A. Lee, K.H. Haller, Supercritical water heat transfer developments and applications, in: Proceedings of the 5th International Heat Transfer Conference, vol. IV, Tokyo, September 3-7 1974, pp. 335-339.

[28] Y. Sudo, K. Miyata, H. Ikawa, M. Kaminaga, M. Ohkawara, Experimental study of differences in DNB heat flux between upflow and downflow in vertical rectangular channel, J. Nucl. Sci. Technol. 22 (8) (1985) 604-618. 